\title{
Quality Criteria for Enterprise Modelling in the context of networked Enterprises
}

\author{
Thomas Knothe ${ }^{1}$, Roland Jochem ${ }^{2}$ \\ ${ }^{1}$ Fraunhofer IPK Berlin, Pascalstraße 8-9 \\ 10587 Berlin, Germany \\ Thomas.Knothe@ipk.fraunhofer.de \\ ${ }^{2}$ University of Kassel \\ Heinrich-Plett-Str. 40, Germany \\ jochem@ifa.uni-kassel.de
}

\begin{abstract}
The capability for collaboration is a key success factor for networked enterprises. The paper introduces a methodology supporting the application of Enterprise Modelling in order to improve the maturity for collaboration. The methodology considers the current status of maturity for interoperability for deducing the right modelling approach. The approach is combined with quality criteria of the models in order to guide the modelling process. Both the deducing approach and the quality criteria are related to the levels of interoperability proposed by the ATHENA Interoperability Framework.
\end{abstract}

\section{Introduction}

Chinese companies in the industrial sector as well Indian ones in the IT sector are entering more and more into the high tech fields of industry by providing very competitive low-cost state of the art products. The reaction of global players in the market can, for instance, be observed in the transfer of less qualified production areas to China in order to reduce costs. This leads sometimes to a shift of the entire production. Especially for European component suppliers this process is very dangerous. Instead of leveraging personal costs, where Europeans have less influence, more offensive approaches are necessary in order to increase competitiveness. Here two aspects are proposed:

o Improving their qualification and capabilities to collaborate with networks and partners. This will enable a single company to join additional business partners in a flexible way or to choose cost effective suppliers based in Eastern Europe.

o Enriching the reputation of the own competencies in order to be recognised in a wide field, as well as to convey trust to potential customers, similar to what Indian software companies had done by achieving Capability Maturity Model (CMM) level 5 for convincing European and American customers to outsource IT development. The most important strength of these types of companies is not anymore exclusively their low labour costs. 
Both activities will lead to higher competitiveness not only in the market of origin, but also for new segments in terms of products and regions. Major barriers are the effort and the time needed to establish collaboration, competence and trust building activities, especially for small and medium sized companies. On the other hand for an SME tools and methodologies, like enterprise modelling as prerequisite for interoperability, are still to much expensive for initial investments, education as well as maintenance.

The goal is to provide an Enterprise Modelling Approach that satisfies together the following conditions:

o Reduction of time to adopt an Enterprise Modelling approach towards interoperability,

o Satisfaction of the users requirements concerning Enterprise Modelling leads to an Enterprise Model with sufficient level of detail, level of formalization and model quality according to the interoperability task,

o Support the daily business of employees especially for interaction between each other.

Another objective of the approach is to enable companies to evaluate their current enterprise interoperability maturity level. A framework determines discrete levels of interoperability improvement based on the successive adoption of good enterprise modelling practices in the different enterprise dimensions (process, organisation, product, systems, etc.).

\section{State of the Art}

The same principle forms the basis of well-known and -introduced maturity models, like, for instance, the CMMI, or SPICE (ISO15504) which help to assess quality aspects of software and system development. There are a lot of Capability Maturity Models available for several business sectors and functions, which already support interoperability aspects (e.g. the collaboration maturity model). However they are not focussing how to achieve interoperability and how to proceed for improving the capabilities.

The tools commonly applied in defining the required steps to achieve a certain level of e-Business implementation come from the areas of Enterprise Modelling (EM), Business Process Modelling (BPM), Workflow Management (WfM) and the like. A plethora of tools supporting the different modelling approaches and paradigms are available on the market in a variety of flavors, features sets, sizes and cost [5]. But the sustainable use of these tools is almost missing. So today, the user of enterprise models has to deal with several problems [1]. First, too much time is needed to create a complete model, and, when finished, the developed model does not reflect the reality in a proper way anymore. Second, the models often don't fit user's requirements, e.g. the model is not detailed enough or the level of formalization is not appropriate. Third, it is often not possible to use the modelling results to support the daily business of employees, because the users most of the time do not have the skills to read the models properly and to deduce the implications for their work. A formal definition of business processes and enterprise assets is however fundamental for being able to 
fully understand and analyse their strategic and operative impact on a company's objectives, and even more for implementing them as e-Business processes.

In the ATHENA project the Establishment methodology for collaborative enterprises was developed, which contains a framework, a methodology, a maturity assessment methodology including a questionnaire, modelling parameters and establishment concepts. In this paper this methodology will be enriched by the integration into the ATHENA Interoperability Framework and by quality criteria which will guide the users for modelling.

\section{Methodology}

\subsection{Approach}

The objective of the framework described in this chapter is to provide a recommendation how to deliver a model-based collaboration, concerning the different levels of collaboration and their optimisation. It shall assist the user in capturing the collaborative processes of the company with the support of one of several adequate modelling approaches. And further it shall support the selection of an adequate methodology within an enterprise model and establish this model in the company. This model shall support to achieve an efficient operation and management of collaboration processes.

Figure 1 gives a review on the whole framework (comp. [1]).

\begin{tabular}{|l|l|}
$\begin{array}{l}\text { Collaboration } \\
\text { Process and Maturity } \\
\text { Assessment } \\
\text { according to the } \\
\text { areas of concern }\end{array}$ & $\begin{array}{l}\text { Mapping the EIMM } \\
\text { with Modelling } \\
\text { Parameters and } \\
\text { Quality Criteria }\end{array}$ \\
\hline
\end{tabular}

Enterprise Model to support interoperability

Figure 1: Model-based collaboration maturity framework

It consists of three parts:

1. Assessment of Collaboration processes and Maturity: The basis is given by the collaborative activities of the company. In order to identify the correct project approach, the maturity assessment has to be performed. Using the maturity model for enterprise modelling that is described in the following section, the result of the first step is supposed to be the maturity level of the company for participating in collaboration. 
2. Deducing the Modelling Approach and the Methodology This step contains the procedure how to deduce an adequate modelling approach and methodology depending on [1]. By the way the modelling parameters have to be specified (e.g. the right level of granularity) as well as the support level of the Model Generated Workplace have to be determined. The conditions are the as is and to be interoperability level according to the EIMM (Enterprise Interoperability Maturity Model), the model quality which is needed to achieve the modeling objective to manage enterprise challenges.

3. Modelling the Enterprise and application: The result of this part is an enterprise model that follows from applying the specific modelling approach and methodology from previous part. This holistic framework includes two levels of implementation (Organisational and Collaboration Instance). Organisational level: The purpose is to improve the overall ability of the enterprise to interoperate with others. The approach is to apply the EIMM. When the enterprise reaches higher maturity levels, it is able to establish collaboration with external entities in a faster, more effective, and more efficient manner, and to make use of the full potential of enterprise modelling approaches. The purpose is to define the adequate enterprise modelling approach to establish collaboration in a specific context. The approach is to characterise the collaboration, identify the model requirements based on that characterisation, and derive the appropriate enterprise modelling recommendations for that requirements.

\subsection{Collaboration processes and Maturity Assessment by using the EIMM}

When applying a maturity assessment for enterprise modelling, we need to examine indicators that allow judging an organization's relative ability to use approaches for representing enterprise knowledge within the organization to improve organizational and personal performance. The traditional way of achieving this ability is to use languages for enterprise modelling, i.e. structure the knowledge representation around graphical (typically two-dimensional) diagrams. Additionally, enterprise modelling practices need to be extended to approach interoperability, in order to facilitate collaboration with others. The following six Areas of Concern can be identified for an EIMM [1]:

o Business Strategy and Processes to cover the identification, specification, execution, improvement and alignment of business strategy and processes. For the purpose of interoperability, this includes and pursues the improvement of internal and external collaborative processes.

o Organisation and Competences to identify knowledge and skills of the targeted players. For the purpose of interoperability, this includes the identification of external entities to collaborate with.

o Products and Services This Area of Concern covers the identification, specification and design of the organisation's products and services, its quality characteristics and the life-cycle strategy. Most important is to check the capability of the company to externalise products und service knowledge in the right granularity and according to the context of collaboration. 
o Systems and Technology to cover the identification, specification, design, construction/acquisition, operation, maintenance and improvement of enterprise systems. The main item is a systematic design and runtime environment to support daily business in a systematic manner.

o Legal Environment, Security and Trust. This Area of Concern covers the identification of legal, security and trust requirements due to the collaboration with external entities, and the provision of solutions to manage these aspects which are a key for interoperability.

All of the previously identified Areas of Concern are directly affected by aspects of an all embracing sixth Area of Concern, which is:

o Enterprise Modelling. This Area of Concern covers the specification, construction, application and improvement of the enterprise models. This includes support activities such as the identification of appropriate metamodels and languages, methodologies, infrastructure, organization (people and skills), etc. for enterprise modelling. Additionally, it deals with the interoperability of enterprise models.

Using a five level maturity scale, the following maturity levels can be identified:

1. Performed: Enterprise modelling and collaboration is done, but in an ad-hoc and chaotic manner. The organization collaborates with external entities (suppliers, administration, customers), but the relationships are not planned thoughtfully. Collaborative tasks and processes usually exceed budget and schedule, their past success (usually based on the people) cannot be repeated.

2. Modelled: Enterprise modelling and collaboration is done in a similar way each time, the technique has been found applicable. People understand the enterprise model and know how to execute it, and network technologies are used to collaborate.

3. Integrated: The enterprise modelling process has been formally documented, communicated and is consistently in use. Different dimensions of the models are integrated among themselves and the model is traceable to the enterprise systems, there is a knowledge base used to improve the models, and business collaboration is facilitated through interoperability technologies, use of standards, and externalisation of part of the enterprise models.

4. Interoperable: Enterprise models support dynamic interoperability and adaptation to changes and evolution of external entities. The workplaces of the people are seamlessly adapted to the enterprise model. Results (for organizations and persons involved) and process metrics are defined as a basis for continuous improvement.

5. Optimising: Enterprise models allow the organisation to react and adapt to changes in the business environment in an agile, flexible and responsive manner. Enterprise systems are systematically traced to enterprise models and innovative technologies are continuously researched and applied to improve interoperability.

The EIMM defined as a set of Areas of Concern and a set of maturity levels provides the means to determine the current ability of an enterprise to collaborate with external entities and to specify the path to improve this ability. It provides an organisational context for more specific and technical improvements. As a third dimension, the EIMM takes into account the targeted organisational units for which a maturity level 
needs to be assessed, or which need to be improved, in order to achieve a certain maturity level. Each Area of Concern will be defined by a set of goals and objectives related to interoperability and collaboration issues. The level of interoperability and collaboration maturity for each Area of Concern will be defined by the presence or absence of maturity indicators. These are typical practices and work-documents, which have to be in place to achieve a determined maturity level. In order to achieve a certain maturity level, each of the indicators needs to fulfill the threshold values or states that are specified for the respective maturity level. At the same time they illustrate the To-Be status that has to be realized if a company wants to reach the next maturity level.

\subsection{Mapping the EIMM with Modelling Parameters and Quality Criteria}

The impact and the benefit of the above described criteria to Interoperability requirements can be shown, if they were mapped to the different levels of the AIF. This mapping of the criteria to the AIF gives the assessment structure and the related procedure a new tool to differentiate and to weight the interoperability requirements for Enterprise Models. In the next two subchapters the Interoperability levels and the quality criteria will be introduced.

\subsubsection{Interoperability levels based on ATHENA Interoperability Framework (AIF)}

The ATHENA Interoperability Framework (AIF) consist on three areas the applicative, the conceptual and the technical integration. Based on the technical framework in Figure 2 the different levels of interoperability are shown. The levels are representing layers of abstraction and the ability of automatically execution of collaboration. In the Business Analyst Perspective means that the involved partners only define common strategic goals which they want to ac hieve together but they do not define how to work together. Models only illustrate these strategic aspects.

Technical Process Analyst Perspective. Collaborations on this level are characterized by the attempt of the partners to align their process with each other. The detailed business logic and the requirements for IT - Support to enable interoperability between business partners can be assessed in this level.

In the third level the Implementation Perspective allows the invocation of existing services automatically. Collaboration can now take place on IT system level by using certain interaction protocols.

The lowest level of granularity is represented by the Data Perspective were data formats and semantics are clarified in order to allow collaboration support with approved data and formats. 


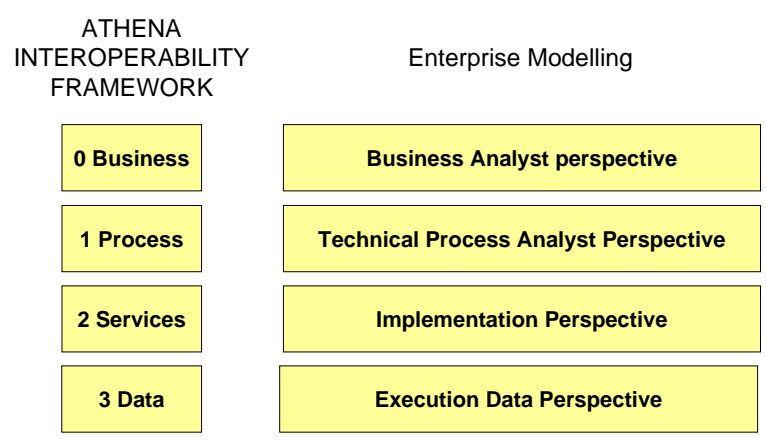

Figure 2: interoperability levels based on the AIF technical framework

3.3.2 Criteria for quality of Enterprise Modelling regarding interoperability

Quality Criteria for Enterprise Modelling regarding interoperability are derived from "Principles of methodical modelling” [7,9] Concepts and Rules for Enterprise Models [6]. These basic criteria are extended and adapted regarding interoperability:

o Correctness: An Enterprise Model is correct, if real world elements are correctly represented in the model. It means syntactically (complete and consistent related to the Meta-Model) and semantically (structural, hierarchical and behavioural constancy related to the elements of the real world) correct. [7]

o Scope and Purpose orientation:An Enterprise Model is scope and purpose oriented, if it represents only these parts of the real world which are intended by the goals, the scope and the purpose of the modeller. [7]

o Efficiency:An Enterprise Model is efficient, if the creation effort is low, but the benefit regarding the intended goals, scope and purpose is high. It is also efficient when the usage duration of the model is long and itself or parts of it are reusable for other goals, scopes and purposes. [7]

o Conformity:An Enterprise Model is conform, if it fulfils specific modelling language requirements, follows specific (design) rules, fulfils/covers standards, covers specific boundary conditions. [7]

o Clearness:An Enterprise Model is „clear“, if on one side a common well known terminology based on an application oriented ontology is used and on the other side it is readable based on a structured layout. This criterion depends on the model user and also on the modelling method/language which is used .[7]

o Comparability:An Enterprise Model is comparable, if it fits into a common framework, uses defined levels of abstraction and a granularity based on defined scope, goals and purpose. Comparability is influenced by the use of common patterns, the grade of formalisation and the correct usage of modelling method/language. [7]

o Systematic Structure:An Enterprise Model has a systematic structure, if it fits into a common framework, uses common pattern, was build with consistent, systematic applied design rules and supports the concepts of views to integrate models developed from different views. [6] 
o Life-Cycle Support:An Enterprise Model supports the Enterprise Life-Cycle, if it allows feeding model information forward and backward in life-cycle activities and represents recursion and iteration mechanisms. Different life-cycle phases may have different models. It enables value-added iteration of enterprise processes that improves product quality. [6,9]

\subsubsection{Mapping}

In Table 1 the mapping between the introduced parameters is shown: Scoping Business Modelling (which are the leading parameters), Modelling parameters, required minimum EIMM Assessment result and importance of the Modelling Quality parameters.

Table 1: Mapping the Modelling parameters according to the scope, EIMM Assessment results and the Importance of Quality Criteria for achieving Interoperability

\begin{tabular}{|c|c|c|c|c|c|}
\hline \multirow{3}{*}{$\begin{array}{c}\text { Modelling } \\
\text { Parameters }\end{array}$} & Model Granularity & Value Chain & Work Process & Activity & Properties \\
\hline & $\begin{array}{l}\text { Model } \\
\text { Completeness }\end{array}$ & Pragmatics & Syntax & $\begin{array}{l}\text { Semantics } \\
\text { constructs }\end{array}$ & Semantics data \\
\hline & $\begin{array}{l}\text { Level of } \\
\text { Formalisation }\end{array}$ & $\begin{array}{l}\text { Business Analyst } \\
\text { Perspective }\end{array}$ & \begin{tabular}{|l} 
Technical \\
Business \\
Process \\
Perspective \\
\end{tabular} & $\begin{array}{l}\text { Implemen- } \\
\text { tation } \\
\text { Perspective }\end{array}$ & $\begin{array}{l}\text { Execution Data } \\
\text { Perspective }\end{array}$ \\
\hline \multirow{4}{*}{$\begin{array}{l}\text { Scoping Business } \\
\text { Modelling }\end{array}$} & $\begin{array}{l}\text { Management } \\
\text { Level }\end{array}$ & $x$ & & & \\
\hline & Process Level & & $x$ & & \\
\hline & $\begin{array}{l}\text { Process Support } \\
\text { Level }\end{array}$ & & & $x$ & \\
\hline & \begin{tabular}{|l|} 
IT-Execution \\
Level - (Data)
\end{tabular} & & & & $x$ \\
\hline $\begin{array}{l}\text { Minimum EIMM } \\
\text { Assessment }\end{array}$ & \begin{tabular}{|l|} 
Products \& \\
Services \\
Enterprise \\
Modelling \\
Legal \\
Environment, \\
Security and \\
Trust \\
Systems \& \\
Technology \\
Business \\
Strategy and \\
Processes \\
Organisation and \\
Competencies \\
\end{tabular} & Level 1 & Level 2 & Level 3 & Level 4 \\
\hline \multirow{8}{*}{$\begin{array}{l}\text { Quality of Model } \\
\text { (0 not important, } 5 \\
\text { highly important) }\end{array}$} & Correctness & Tmportant & Tmportant & Tmportant & Essential \\
\hline & $\begin{array}{l}\text { Scope and } \\
\text { Purpose } \\
\text { orientation }\end{array}$ & Essential & Essential & Important & Less important \\
\hline & Efficiency & Less important & Less important & Less important & Important \\
\hline & Conformity & Important & Important & Important & Essential \\
\hline & Clearness & Essential & Tmportant & Tmportant & Tmportant \\
\hline & Comparability & Tmportant & Essential & Essential & Essential \\
\hline & $\begin{array}{l}\text { Systematic } \\
\text { Structure }\end{array}$ & Important & Essential & Essential & Essential \\
\hline & $\begin{array}{l}\text { Life-Cycle } \\
\text { Support }\end{array}$ & Essential & Essential & Important & Less important \\
\hline
\end{tabular}


The AIF levels are represented as Level of Formalisation from Business Analyst perspective to Execution Data perspective. Based on the "Business Scope" the right modelling parameters can be derived in order to define an appropriate model (see mark " $X$ " to each level). As well the required EIMM level is indicated in the same metric. In the case that an EIMM level is not achieved for a distinct modelling task, activities for the improvement of interoperability capabilities can be identified by a simple analysis of the current maturity profile. The quality parameter which represents the outcome of the modelling task has a different behaviour. The requirements level of each parameter is increasing from left to right. So for instance becomes the "Clearness" in the Execution Data Perspective the mark important whilst in the other levels it is essential.

\subsection{Application in the context of networked enterprises}

The establishment approach is today defined in a very generic manner. This will allow the application of this concept for a lot of different purposes and the approach will become more important when adopting special needs. In the following some specific items for deriving the approach are explained [1]:

Interoperability Assessment (IAS) for Supplier or Supplier Network Participants: A lot of suppliers (especially in the automotive sector) are challenged by serving to a multitude of OEM's, because of different specifications in terms of processes, IT-systems, documents and organisation. Implementing Industrial Reference Models: Companies have to take into account reference and sometimes best practice approaches (e.g. ITIL). For being compliant to these reference models companies need very deep definitions of their own business and have to change their processes and infrastructure. Therefore the EIMM should be adopted according to the specific needs. For the other elements of the entire establishment approach there is no change required.

o Support for Certification: A lot of reference models of the above explained challenge e.g. ITIL are a basis for several sector specific and sector independent certifications. The establishment framework can support the process of certification preparation and bring these activity inline with the overall business activities. The EIMM itself will be applicable for most of the standards in order to measure the company situation according to the specific standard requirements.

\section{$4 \quad$ Summary and Outlook}

The Framework for the Establishment and Management Methodology and their concepts that are mainly elaborated in ATHENA A1 and described (such as EIMM and Maturity Assessment, Deducing Modelling Approach with Modelling Parameters, Establishment Methodology and Mapping Method) has as goal the improved utilisa- 
tion of enterprise modelling to enable the enterprises to have efficient collaboration with each other.The application of these concepts allows the enterprises first to create the enterprise models for improving the interoperability capabilities in short time with using a modelling approach that is adapted to the specific enterprise requirements. Second to keep the developed models alive and to use them to support the daily business of employees. Third to follow incremental and thus more controllable approaches for applying enterprise modelling in order to improve the business.

The usefulness and expedience of the concepts is validated in the use cases that based on the industrial projects. In the next steps the relationship between the deducing approach for enterprise modelling and establishment concepts has to be verified.

\section{Acknowledgements}

Basic requirements were elaborated during the UEML Thematic Network project Contract $n^{\circ}$ : IST - $2001-34229$.

The EIMM and the establishment methodology were developed in the ATHENA Integrated Project Contract $n^{\circ}:$ IST-507849. The proposed interoperability framework is used from the A4 project of the ATHENA IP. The content will be used for the PhD thesis of Thomas Knothe.

\section{References}

1. Knothe, T., Schneider, K., Böll, D., Kahl, T., Schuster, S., Lillehagen, F., Krogstie, J., Grenager Solheim, H.: First Version of Establishing and management approach, Deliverable - A1.4.1, ATHENA, Integrated Project - Contract n:IST-507849 (2005), www.athenaip.org

2. Carnegie Mellon ${ }^{\circledR}$ Software Engineering Institute: SEI Software Engineering Process Management Program, 17.12.2004, ttp://www.sei.cmu.edu/organization/programs/sepm/process.html

3. Knothe T., Busselt, C., Böll, D.: Deliverable D2.3 Report on UEML (Needs and Requirements), UEML, Thematic Network (2003), www.ueml.org

4. Mertins, K., Knothe, T., Zelm, M.: User oriented Enterprise Modelling for Interoperability with UEML, in EMMSAD’04, RIGA, Latvia, 7-8 June, 2004

5. Garcia A. B. et all: DA.1.1.1 - State of the Art in EM Techniques and Technologies to Support Enterprise Interoperability, ATHENA, Integrated Project - Contract $n^{\circ}:$ IST-507849 (2005), www.athena-ip.org

6. Jochem, R.: Integrierte Unternehmensplanung auf der Basis von Unternehmensmodellen, Dissertation TU-Berlin (2001)

7. Becker, J., M. Rosemann, R. Schütte: Grundsätze ordnungsmäßiger Modellierung. Wirtschaftsinformatik, 37 (1995) 5, 435-445.

8. Krogstie, John "Process improvement as organizational development: A case study on the introduction and improvement of information system processes in a Norwegian organization.” in NOKOBIT'2000. 2000. Bodø, Norway.

9. ISO 14258 Industrial Automation Systems - Concepts and Rules for Enterprise Models 